\title{
A new device to prevent fascial retraction in the open abdomen - proof of concept in vivo
}

\author{
Roman Eickhoff ${ }^{1 *}$ (D), Maria Guschlbauer ${ }^{2,5}$, Alexandra C. Maul ${ }^{2}$, Christian D. Klink', Ulf P. Neumann ${ }^{1}$, Michael Engel ${ }^{3}$, \\ Martin Hellmich ${ }^{4}$, Anja Sterner-Kock ${ }^{2}$ and Christian F. Krieglstein ${ }^{3}$
}

\begin{abstract}
Background: An open abdomen is often necessary for survival of patients after peritonitis, compartment syndrome, or in damage control surgery. However, abdominal wall retraction relieves delays and complicates abdominal wall closure. The principle of the newly fascia preserving device (FPD) is the application of anteriorly directed traction on both fascial edges over an external support through a longitudinal beam to relieve increased abdominal pressure and prevent fascial retraction.

Methods: Twelve pigs were randomly divided into two groups. Both groups underwent midline laparotomy under general anesthesia. Group one was treated with the new device, group two served as controls. The tension for closing the abdominal fascia was measured immediately after laparotomy as well as at 24 and $48 \mathrm{~h}$. Vital parameters and ventilation pressure were recorded. Post mortem, all fascial tissues were histologically examined.

Results: All pigs demonstrated increases in abdominal circumference. In both groups, forces for closing the abdomen increased over the observation period. Concerning the central closing force after $24 \mathrm{~h}$ we saw a significant lower force in the FPD group $(14.4 \pm 3 \mathrm{~N})$ vs. control group $(21.6 \pm 5.7 \mathrm{~N}, p<0.001)$. By testing the main effects using an ANOVA analysis we found a significant group related effect concerning closing force and abdominal circumference of the FDP-group vs. control group $(p<0.001 ; p<0.001)$. The placement of the device on chest and pelvis did not influence vital parameters and ventilation pressure. Histologic exam detected no tissue damage.

Conclusions: This trial shows the feasibility to prevent fascial retraction during the open abdomen by using the new device. Thus, it is expected that an earlier closure of the abdominal wall will be possible, and a higher rate of primary closure will be attained.
\end{abstract}

Keywords: Open Abdomen; Laparostoma, Fascial traction, Linea alba, Open abdomen

\section{Background}

An open abdomen is often necessary for survival of patients after peritonitis, compartment syndrome, or in damage control surgery e.g. after trauma [1]. The increased intraabdominal volume in the presence of visceral swelling requires a large area of the abdomen to be left open after laparotomy to prevent pressure-induced necrosis of the organs and tissues [2]. In this situation, the tension from the musculature acting on the abdominal wall

\footnotetext{
* Correspondence: reickhoff@ukaachen.de

'Department of General, Visceral and Transplantation Surgery, RWTH Aachen University Hospital, Pauwelsstraße 30, 52074 Aachen, Germany

Full list of author information is available at the end of the article
}

resulting in a gradual retraction of the wound-, respectively the fascia edges [3].

The current standard of care is to treat the open abdomen with negative pressure therapy or with other types of temporary abdominal closure [4]. The most common method is the vacuum dressing on the abdominal wound and organs $[5,6]$. In this case, a sealed dressing is guaranteed, and edema is drained through the vacuum system pump. Particularly good results have been attained by vacuum therapy combined with fascial traction, whether with interpolated mesh (vacuum-assisted wound closure and mesh-mediated fascial traction, VAWCM) or for example, $\mathrm{ABRA}^{\circ}$ abdominal wall closure [7]. Here, however, fascial

C The Author(s). 2019 Open Access This article is distributed under the terms of the Creative Commons Attribution 4.0 International License (http://creativecommons.org/licenses/by/4.0/), which permits unrestricted use, distribution, and reproduction in any medium, provided you give appropriate credit to the original author(s) and the source, provide a link to the Creative Commons license, and indicate if changes were made. The Creative Commons Public Domain Dedication waiver (http://creativecommons.org/publicdomain/zero/1.0/) applies to the data made available in this article, unless otherwise stated. 
traction is only possible once the intraabdominal volume and pressure have diminished, since traction from one fascial border to the next is impeded by the protruding abdominal organs. All methods of temporary abdominal closure to date have been insufficient to counteract abdominal wall retraction, and can only, if any, perform higher traction on the fascia by stepwise closing of the fascia during re-laparotomy [8].

Delayed abdominal closure then often requires alloplastic grafting or results in a permanent abdominal wall defect, which is resulting in a so called "planned ventral hernia" [9-11]. These ventral hernias have to be repaired in a second operation with a reconstruction of the abdominal wall [11]. Longer duration of an open abdomen is also associated with bowel adhesions, fistula formation, and loss of abdominal wall tissue [11-19]. Mortality of the open abdomen has been reported as $12-40 \%$, with septic etiology associated with increased rates [1]. Hecker et al. found a dramatically increased complication rate after 8 days of open abdomen therapy [20]. Therefore, early closure should be the goal. In trauma patients undergoing abdominal closure within $48 \mathrm{~h}$, there is a more favorable hospital course, lower complication rates, and decreased mortality [21-23].

From this background emerged the idea for a new device that both allows decompression of increased abdominal pressure and prevents fascial retraction immediately after surgery. As no clinical experience is available for the new investigational device, a porcine animal model was chosen for acquiring primary data on effectiveness and safety because area and tension ratio of the abdominal wall are well comparable to those in humans.

\section{Methods}

\section{Device description}

The basic principle of the device is application of ventrally-directed traction along both fascial edges over an external support (Figs. 1 and 2). It consists of a beam with two buttresses applied to the thorax and anterior pelvic ring. After opening of the abdomen, the laparotomy edges are looped using commercial sutures and a surgical mesh which distributes traction force along the entire length of the fascial edges. The sutures are carried through eyelets fastened to a common suspension. The eyelet suspension is fixed to the longitudinal beam with a height-adjustable connection. Using this dynamic connection, the fascial traction can be increased or decreased as needed. The fascial edges are pulled anteriorly relative to the thorax and pelvis. This counteracts the natural muscle traction and the resulting fascial retraction. At the same time, the open abdomen allows pressure release. Extensive tissue can develop anteriorly. In principle, temporary closure of the open abdomen

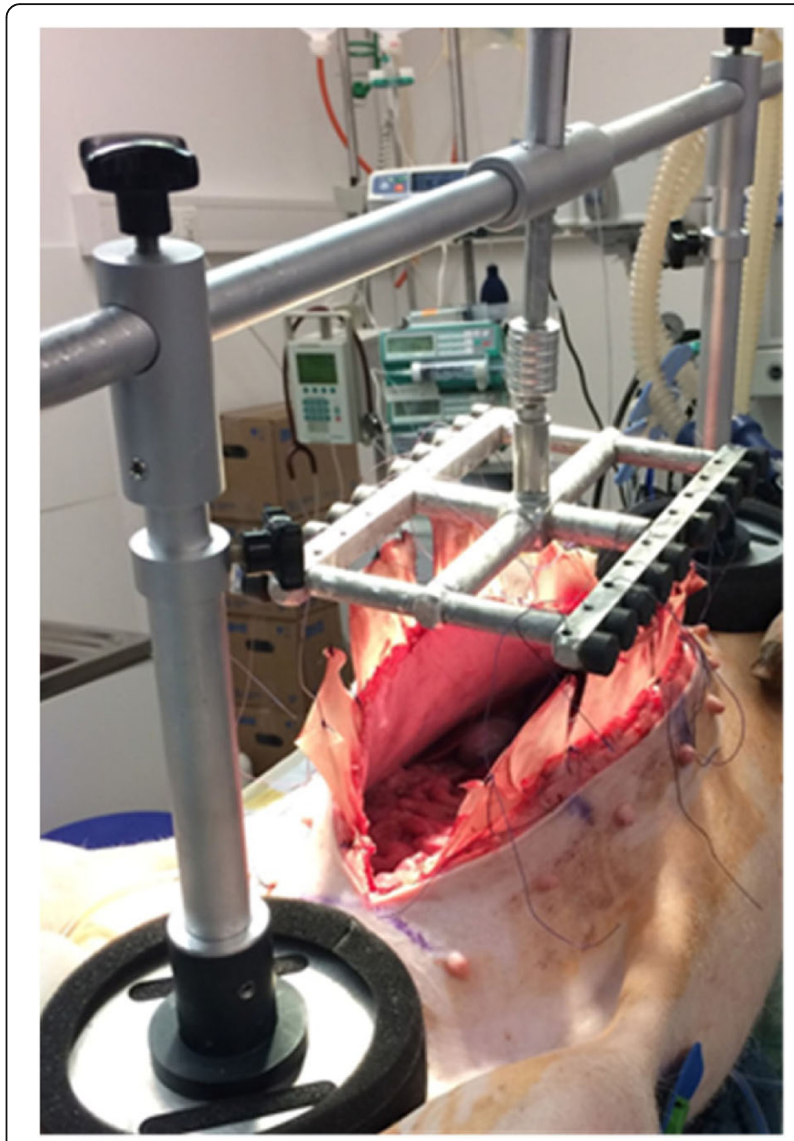

Fig. 1 FPD applied to a pig under general anesthesia

can now be performed with all typical measures. Conventional or commercial vacuum dressings can be placed between the tent-shaped suture suspensions. Figure 1 shows a third-generation prototype applied to a pig under general anesthesia.

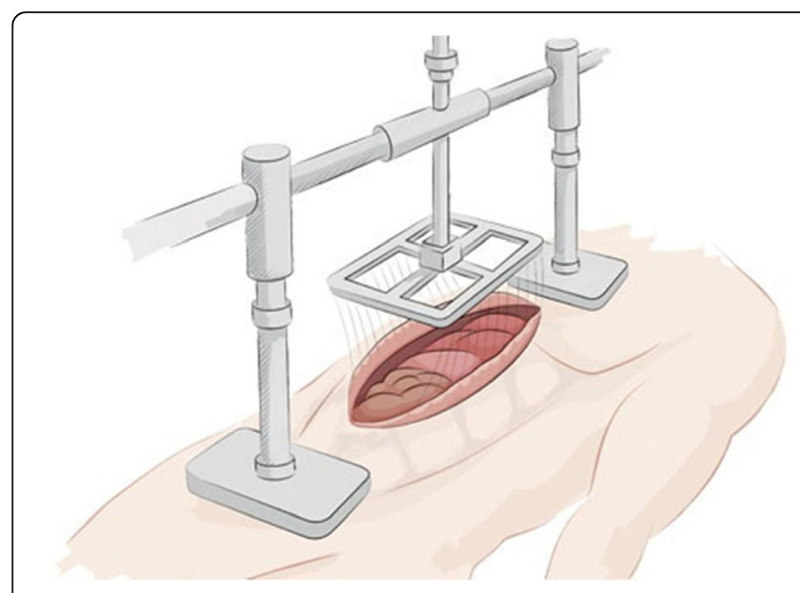

Fig. 2 Potential setting of the fascia preserving device in a clinical prospective study. (Source: Fasciotens) 


\section{Animal test protocol}

All experiments were in accordance with the German legislation governing animal studies and the Guide for the Care and Use of Laboratory Animals (National Institutes of Health (NIH), Publication No 85-23, revised 2011). The experiments were approved by the Governmental Animal Care and Use Committee (LANUV, Landesamt für Natur Umwelt und Verbraucherschutz NordrheinWestfalen, Recklinghausen, Germany) (reference number: 84-02.04.2015.A584). All pigs were housed in groups of 3-5 in the Institution minimum 10 days before the first treatment for acclimatization after a medical baseline examination. Animals were kept under standardized and hygienic optimized conditions on litter: temperature between $21^{\circ} \mathrm{C}$ and $23{ }^{\circ} \mathrm{C}$; relative humidity $50-60 \%$; and 12 $\mathrm{h} / 12 \mathrm{~h}$ of light/dark cycle. They got free access to water and got food 3\% / kg bodyweight / day. Animals were obtained from a breeding facility (pig feeding farm, Kalkar, Germany). Twelve female pigs of $25-30 \mathrm{~kg}$ were randomly divided into two groups. Six animals per group were the smallest calculated group size to show a potential significant effect (effect size, Cohen's d 0.5) for the primary outcome parameter. The experiment duration was $48 \mathrm{~h}$ after initiation of anesthesia in the operating room without awakening afterwards. Primary endpoint was the closing force after $24 \mathrm{~h}$.

\section{Surgical procedure}

Operative treatment was carried out under standardized conditions. Both groups underwent midline laparotomy with $30 \mathrm{~cm}$ incision centered between symphysis and xiphoid under general intra-venous anesthesia (Fentanyl: $0.025 \mathrm{mg} / \mathrm{kg}$ BW/h, Propofol: 4-6 mg/kg BW/h and Midazolam: $0.96-1.2 \mathrm{mg} / \mathrm{kg} \mathrm{BW/h}$ ) and volume-controlled ventilation. Anaesthesia was controlled by continuous measuring of ECG, arterial blood pressure, capnometry and respiratory minute volume. All fascial edges were looped with Vicryl $^{\bullet}$ mesh pieces fixed with Vicryl ${ }^{\bullet}$ sutures size 2-0 (Ethicon, Cincinnati, Ohio, USA). Group one was treated with the new device. With this device, anteriorly-directed traction was applied to both sides of the abdominal wall for $48 \mathrm{~h} .40 \mathrm{~N}$ of constant traction were applied with the device bearing on the thorax and anterior pelvic ring. Traction was checked and readjusted every hour as needed. Group two underwent midline laparotomy with $\mathrm{Vicryl}^{\circ}$ mesh looped to both fascial edges to ensure blinding of the histological assessment. No other surgical procedures were performed. All pigs received a prophylactic single-shot dose of amoxicillin (150 mg/10 kg weight).

The tension for the approximation of both fascial edges was measured immediately after laparotomy as well as at 24 and $48 \mathrm{~h}$ with (Pesola ${ }^{\circ}$ Precision scale $25 \mathrm{~N}$, Switzerland) . Measurements were performed at the laparotomy incision center as well as $7.5 \mathrm{~cm}$ cranially and caudally, and repeated three times at each point. Mean values were used for further calculations. The tension in the laparotomy's center at $24 \mathrm{~h}$ was defined as primary endpoint for this trial. During all measurements, the pigs received pancuronium as a muscle relaxant with a bolus dose of $0.36 \mathrm{mg} / \mathrm{kg}$ followed by continuous infusion of $0.36 \mathrm{mg} / \mathrm{kg} / \mathrm{h}$. At determined closing forces of 5,10 , and $15 \mathrm{~N}$, distance between the fascial edges was measured (Pesola ${ }^{\oplus}$ Precision scale $25 \mathrm{~N}$, Switzerland). Vital parameters and ventilation pressure were recorded during the entire observation period. For analysis, mean values were taken from 4 hour intervals, yielding 12 periods of vital and ventilation parameter measurements.

Post-mortem, histologically investigations were performed on paraffin embedded $3 \mu \mathrm{m}$ sections after fixation of the samples for $48 \mathrm{~h}$ in $4 \%$ formalin. All sections were routinely stained with haematoxylin and eosin. For pathologist blinding, samples of skin, subcutaneous tissues and fascial edges of all animals, including the controls, were submitted. The laparotomy edges including skin, subcutaneous tissues and abdominal wall fascia as well as abdominal musculature and the attached mesh were also sent for analysis.

All pigs were euthanized after $48 \mathrm{~h}$ with an overdose of pentobarbital $(160 \mathrm{mg} / \mathrm{kg} \mathrm{BW})$.

\section{Statistical analysis}

Differences in means between groups were evaluated by a non-parametric Mann-Whitney U-Test. Change relative to baseline at each of the measurements was analyzed using an ANOVA with the factors "group", "location", "time-point", testing for the main effects and interactions between group and location as well as time-point. $P$-values smaller than 0.05 were considered to be statistically significant. All values are expressed as mean \pm SD and median (in brackets) if not otherwise mentioned.

\section{Results}

One pig in the control group died $36 \mathrm{~h}$ after laparotomy. Another pig in the control group was resuscitated after $33 \mathrm{~h}$ but survived the observation period afterwards. Therefore $n=11$ pigs (Control $n=5$, FPD-group $n=6$ ) were observed over the entire 48 -h period.

Mean operative time was $44 \mathrm{~min}$ (range $30-55 \mathrm{~min}$ ) in the FPD group and $40 \mathrm{~min}$ (range $29-66 \mathrm{~min}$ ) in the control group $(p<0.85)$. Histological examination of the analyzed samples, especially the facial edges after $48 \mathrm{~h}$ of traction showed no necrosis or increased inflammatory reaction in the FPD-group in comparison to controls.

Abdominal circumference increased in both groups over the $48 \mathrm{~h}$ observation period. There was no significant difference between the groups $(p>0.69$, Table 1$)$. 
Table 1 Abdominal circumference in $\mathrm{cm}$. Mean value and standard deviation and median (in bracket) are given for the individual measuring points of both groups. P-values are indicated for subgroup comparison

\begin{tabular}{|c|c|c|c|c|c|c|c|c|c|}
\hline & \multicolumn{3}{|l|}{ Baseline } & \multicolumn{3}{|l|}{$24 \mathrm{~h}$} & \multicolumn{3}{|l|}{$48 \mathrm{~h}$} \\
\hline & $\overline{F P D}$ & Control & $p$ & FPD & Control & $p$ & FPD & Control & $p$ \\
\hline Cranial & $71.4 \pm 1.5(71)$ & $71.3 \pm 1.5(71.5)$ & 1.0 & $77.7 \pm 4.5(75.5)$ & $77.2 \pm 4.3(76)$ & 0.699 & $85 \pm 2.1$ (86) & $84.8 \pm 7(83)$ & 0.841 \\
\hline Central & $71.2 \pm 2.2(70)$ & $70.7 \pm 1(70)$ & 1.0 & $78.1 \pm 4.5(77)$ & $77.7 \pm 4.5(76)$ & 0.937 & $87 \pm 2.4(83)$ & $86.7 \pm 8.1(82)$ & 0.69 \\
\hline Caudal & $70 \pm 2.8(69)$ & $69.6 \pm 1.7(70)$ & 1.0 & $75.2 \pm 3.4(74.5)$ & $74.8 \pm 4(73.5)$ & 0.818 & $88 \pm 2.1(87)$ & $84.4 \pm 7(87)$ & 0.69 \\
\hline
\end{tabular}

Concerning the primary endpoint of this study the central closing force after $24 \mathrm{~h}$ we saw a significant lower force in the FPD group $(14 \pm 3 \mathrm{~N})$ vs. control group $(22 \pm 6, p<0.001)$. In addition at the caudal and cranial measurement point the forces were also significant lower in the FPD group (cranial: $13.1 \pm 2.0 \mathrm{~N}$ vs. $18.3 \pm 6.2 \mathrm{~N}$, $p<0.04$; caudal $11.5 \pm 2.9$ vs. $16.4 \pm 6.3 \mathrm{~N}, p<0.011$ ). After $48 \mathrm{~h}$ the force for closing the abdomen was lower in the FPD group compared to the control, but only significant in the caudal measure point $(20.5 \pm 6.7 \mathrm{~N}$ vs. $31.5 \pm 17.6 \mathrm{~N}, p<0.029)$. The force for closing the abdomen increases in both groups over the observation period (Table 2). In correlation to the results of the required force for closing the abdomen the measured distances between the fascial edges at defined forces shows correspondent findings: After $24 \mathrm{~h}$ there was a significant smaller distance between the fascia edges with a defined force of $5 \mathrm{~N}$ and $10 \mathrm{~N}$ at central and caudal measurement point $(5 \mathrm{~N}$ : central $p<0.005$, caudal $p<$ $0.02 ; 10 \mathrm{~N}$ : central $p<0.00$, caudal $p<0.029)$. After $48 \mathrm{~h}$ the distance between the fascial edges were significant smaller at a caudal measurement point at all forces $(5 \mathrm{~N}$, $p<0.013 ; 10 \mathrm{~N}: p<0.002 ; 15 \mathrm{~N}: p<0.01$ ) (Table 3).

Over the 12 measuring periods in $48 \mathrm{~h}$, the parameters of heart rate, temperature, end-expiratory $\mathrm{CO} 2, \mathrm{O} 2$ saturation, arterial pressure, $\mathrm{FiO} 2$, maximum air pressure, tidal volume, and PEEP did not differ significantly between the two groups.

\section{Longitudinal model (ANOVA) analysis}

By testing the main effects using an ANOVA analysis we found a significant group related effect concerning closing force and abdominal circumference of the FDP-group vs. control group ( $p<0.001 ; p<0.001)$.
Furthermore the analysis of outcome parameter "abdominal circumference" shows following results: group effect $p<0.001$; location $p=0.31$; time-point $p<0.001$. We found no significant result for group $\mathrm{x}$ time-point, group $\mathrm{x}$ location and group $\mathrm{x}$ location $\mathrm{x}$ time-point interaction $(p=0.27 ; p=0.87 ; p=0.67)$. The detailed analysis of outcome parameter "closing force" is as follows: group effect $\mathrm{p}<0.001$; location $p=0.001$; time-point $\mathrm{p}<0.001$. We found a significant group $\mathrm{x}$ time-point and group $\mathrm{x}$ location interaction $(p=0.02 ; p=0.03)$, but no significant effect of group $\mathrm{x}$ location $\mathrm{x}$ time-point interaction $(p=0.24)$.

\section{Discussion}

This study shows the feasibility of treating the open abdomen using the new fascia preserving device (FPD) with a significant lower fascial tension $24 \mathrm{~h}$ after laparotomy at a central measurement point and a significant overall group related effect concerning closing force and abdominal circumference.

Reconstruction of the abdominal wall after an open abdomen still presents a surgical challenge [24]. The device could offer a significant improvement to existing treatments. However, it is important to consider the forces of tension and pressure. At the fascial borders, strong tensile forces may cause tissue necrosis over time.

To date, mechanical properties of the abdominal wall have been investigated ex vivo or with non-invasive methods [25]. To our knowledge, traction applied to fascia in vivo over several days has not been previously investigated. The forces, with which the fascial edges need to be brought together for closure, have also not been previously quantified.

Table 2 Closing Forces (in Newton). Mean value and standard deviation and median (in bracket) are given for the individual measuring points of both groups. P-values are indicated for subgroup comparison. The primary endpoint of the study is highlighted in gray

\begin{tabular}{|c|c|c|c|c|c|c|c|c|c|}
\hline & \multicolumn{3}{|l|}{ Baseline } & \multicolumn{3}{|l|}{$24 \mathrm{~h}$} & \multicolumn{3}{|l|}{$48 \mathrm{~h}$} \\
\hline & FPD & Control & $p$ & FPD & Control & $p$ & FPD & Control & $p$ \\
\hline Cranial & $8.5 \pm 1.0(9)$ & $7.3 \pm 1.8(7.25)$ & 0.031 & $13.1 \pm 2.0(13)$ & $18.3 \pm 6.2(15)$ & 0.040 & $27.3 \pm 7.3(29)$ & $34.6 \pm 19.3(25)$ & 0.512 \\
\hline Central & $10.2 \pm 2.7(9)$ & $10.6 \pm 1.8(10.5)$ & 0.239 & $14.4 \pm 3.0(15)$ & $21.6 \pm 5.7(19.5)$ & $<0.001$ & $29.9 \pm 10.1$ (29.5) & $37.8 \pm 15.5$ (29.5) & 0.148 \\
\hline Caudal & $8.2 \pm 1.4(8.5)$ & $7.4 \pm 1.3(7)$ & 0.079 & $11.5 \pm 2.9(12.5)$ & $16.4 \pm 6.3(15.25)$ & 0.011 & $20.5 \pm 6.7(17)$ & $31.5 \pm 17.6(22)$ & 0.029 \\
\hline
\end{tabular}


Table 3 Distance between the fascial margins with defined traction in $\mathrm{cm}$. Mean values and standard deviation and median (in bracket) for both groups and $p$-values for sub-group comparison

\begin{tabular}{|c|c|c|c|c|c|c|c|c|c|c|}
\hline & & \multicolumn{3}{|l|}{ Baseline } & \multicolumn{3}{|l|}{$24 \mathrm{~h}$} & \multicolumn{3}{|l|}{$48 \mathrm{~h}$} \\
\hline & & FPD & Control & $p$ & FPD & Control & $p$ & FPD & Control & $p$ \\
\hline \multirow[t]{3}{*}{$5 \mathrm{~N}$} & Cranial & $\pm 0.2(1.05)$ & $0.7 \pm 0.6(0.5)$ & 0.006 & $2.0 \pm 0.2(2.05)$ & $2.7 \pm 0.8(2.35)$ & 0.074 & $4.0 \pm 0.8(4.1)$ & $4.9 \pm 1.8(4.1)$ & 0.367 \\
\hline & Central & $1.8 \pm 0.9(1.65)$ & $1.8 \pm 0.9(1.7)$ & 0.938 & $3.0 \pm 0.6(3.1)$ & $4.4 \pm 1.0(3.8)$ & 0.005 & $5.6 \pm 1.1(6)$ & $6.7 \pm 1.5(6)$ & 0.137 \\
\hline & Caudal & $0.9 \pm 0.6(0)$ & $0.9 \pm 0.6(0.8)$ & 0.091 & $1.6 \pm 0.9(2.05)$ & $2.8 \pm 1.0(2.6)$ & 0.020 & $3.6 \pm 1.0(3)$ & $5.0 \pm 1.6(4.5)$ & 0.013 \\
\hline \multirow[t]{3}{*}{$10 N$} & Cranial & $\pm 0.1(0.0)$ & $0.1 \pm 0.1(0)$ & 0.888 & $0.4 \pm 0.3(0.55)$ & $1.1 \pm 1.1(0.6)$ & 0.372 & $2.6 \pm 1.0(2.9)$ & $3.5 \pm 1.9(2.6)$ & 0.367 \\
\hline & Central & $0.3 \pm 0.6(0.0)$ & $0.2 \pm 0.5(0)$ & 0.938 & $0.8 \pm 0.6(1.1)$ & $2.5 \pm 1.2(1.85)$ & $<0.001$ & $3.5 \pm 1.4(4)$ & $4.7 \pm 1.7(4.2)$ & 0.106 \\
\hline & Caudal & $\pm 0.0(0.0)$ & $0.2 \pm 0.3(0)$ & 0.406 & $0.4 \pm 0.4(0.45)$ & $1.1 \pm 1.0(0.8)$ & 0.029 & $1.6 \pm 1.1(1.4)$ & $3.2 \pm 1.6(2.6)$ & 0.002 \\
\hline \multirow[t]{3}{*}{$15 N$} & Cranial & $\pm 0.0(0.0)$ & $0.0 \pm 0.0(0.0)$ & 1.000 & $0.0 \pm 0.0(0.0)$ & $0.4 \pm 0.8(0.0)$ & 0.888 & $1.5 \pm 1.1(2)$ & $2.5 \pm 2.1$ & 0.345 \\
\hline & Central & $\pm 0.0(0.0)$ & $0.0 \pm 0.0(0.0)$ & 1.000 & $0.0 \pm 0.0(0.0)$ & $0.7 \pm 1.0(0.35)$ & 0.001 & $2.0 \pm 1.5(2.7)$ & $3.1 \pm 1.8(2.4)$ & 0.174 \\
\hline & Caudal & $0.0 \pm 0.0(0.0)$ & $0.0 \pm 0.0(0.0)$ & 1.000 & $0.0 \pm 0.0(0.0)$ & $0.4 \pm 0.5(0.0)$ & 0.091 & $0.7 \pm 1.0(0.2)$ & $2.0 \pm 1.8(1.5)$ & 0.010 \\
\hline
\end{tabular}

Data in bold are significant $p$-values

Thus, the current study presents a reference regarding the forces exerted on the abdominal wall fascia of pigs. Due to systemic inflammation and generalized edema, all pigs demonstrated an increasing abdominal circumference during the $48 \mathrm{~h}$. It is important to consider that body weight, abdominal wall condition, and intra-abdominal volume increases markedly the traction forces. These conditions cannot be adequately reflected in a living pig model. The closing force needed for primary or secondary abdominal wall closure remains unclear as well. The decision of whether the applied tension is reasonable for the suture material has been left to the discretion of the surgeon. In the current study, histological examinations revealed no fascial edge lesions. Thus, it can also be assumed that further increases of traction with the fascia preserving device are possible, and perhaps even necessary. This should be clarified in further studies.

The pressure created on the bearing surfaces initially appeared to be the largest challenge in application of the new device. Because here as well there is no available basic data, published data regarding the development of decubital ulcers was referred to when constructing the device. Their occurrence, particularly on the sacrum and heels of bedridden patients, has been investigated several times.

For the development of pressure ulcers, interruption of the capillary blood supply in particular is considered relevant. Various studies have quoted limiting values as $32-70 \mathrm{mmHg}$ [26-28]. $32 \mathrm{mmHg}$ corresponds approximately to a pressure of $43.5 \mathrm{~g} / \mathrm{cm}^{2}$. The presented prototype for the porcine model has supports with approximate surface area of $66 \mathrm{~cm}^{2}$ per post. Thus, interruption to the skin capillary circulation would be expected with $5742 \mathrm{~g}$ of pressure in total.

The resulting pressure came from the weight of the device and the applied tensile forces. The latter corresponds to an approximate pressure load of $4 \mathrm{~kg}$ at $40 \mathrm{~N}$, plus the weight of $1.5 \mathrm{~kg}$. With this level of pressure, no pressure lesions were evident on the histological samples. For humans, increased traction might be necessary to prevent retraction of the abdominal wall fascia. The support surfaces used here, with surface areas of $2 \times 300 \mathrm{~cm}^{2}$, are significantly larger and according to the calculations above would allow a traction pressure load up to $26100 \mathrm{~g}$.

Another question of the current study was whether enduring pressure on the thorax would affect breathing and vital signs. To date, here also no studies have been published. Most of the investigated parameters did not differ significantly between the two groups. No effects on either ventilation or hemodynamics were evident in the study group.

One limiting factor of the current study is that the observation period, with $48 \mathrm{~h}$, is relatively brief compared to the average intensive care time of patients. Unfortunately, this has to do with the behavior of pigs under general anesthesia, which makes longer observation difficult. In addition, various factors must be included when evaluating the new device for human use. Body weight and intra-abdominal volume as mechanical factors, but also medical conditions like sepsis, renal function, and associated cardiopulmonary diseases could influence treatment with the new device.

As mentioned above, the open abdomen is associated with high morbidity and mortality $[1,10]$. In addition, there are significant socioeconomic costs to consider. These range from the direct medical costs of long inpatient stays with necessary intensive care and repeated surgeries, to indirect costs from disability and inability to work. In addition, affected patients experience substantial detriments to quality of life, for example, from defective healing and large abdominal wall hernias, as well as subsequent surgeries due to abdominal wall reconstruction $[11,29]$.

The current standard of NPWT therapy is associated with an unacceptably high rate of incisional hernias. In long-term follow-up, Hofmann et al. identified incisional hernias in a third of patients [24]. 
Knowing the consequences of an open abdomen, improvement of life quality for affected patients should be a substantial goal. An increased rate of primary abdominal wall closure would be a marked improvement according to these authors [11]. If the device works as theorized, there will also be substantial cost-saving potential through the shortened duration of intensive care and opened abdomen, as well as fewer operative interventions. It is still unclear whether treatment without vacuum bandage will be helpful. If so, further moneysaving is possible.

Prior to use in human patients, however, further technical improvements are ongoing and we are looking forward for the first clinical trial (Fig. 2).

\section{Conclusions}

With all of these considerations, this new device offers a promising approach as an innovative treatment option. We could demonstrate the feasibility and effectivity regarding fascial conditioning. This counteracts the retraction of the abdominal wall. Thus, it is expected that an earlier closure of the abdominal wall will be possible, and a higher rate of primary closure will be attained.

\begin{abstract}
Abbreviations
BW: Bodyweight; FiO2: Fraction of inspired oxygen; FPD: Fascia Preserving Device; H: Hour; Min: Minute; N: Newton; NIH: National Institutes of Health; NPWT: Negative-pressure wound therapy; PEEP: Positive end-expiratory pressure; VAWCM: Vacuum-assisted wound closure and mesh-mediated fascial traction
\end{abstract}

\section{Acknowledgements}

Not applicable.

\section{Authors' contributions}

All authors meet the qualifications for authorship and they have read and approved the submitted manuscript. Study conception and design: RE; MG; CFK; MH; AS-K. Acquisition of data: MG; ACM; MG; ME; MH; AS-K. Analysis and interpretation of data: RE; CDK; CFK; MG; ACM; MH. Drafting of manuscript: RE; CDK; UPN; CFK. Critical revision of manuscript: RE; CFK; CDK; UPN; MG; ACM; ME; MH; AS-K.

\section{Funding}

Fasciotens $\mathrm{GmbH}$ (Cologne, Germany) provided the devices and financial support for the trial. Fasciotens $\mathrm{GmbH}$ was involved in the study conception and design, but not involved in collection, analysis, and interpretation of data and in writing the manuscript.

\section{Availability of data and materials}

The datasets used and analysed during the current study are available from the corresponding author on reasonable request.

\section{Ethics approval and consent to participate}

All experiments were in accordance with the German legislation governing animal studies and the Guide for the Care and Use of Laboratory Animals (National Institutes of Health (NIH), Publication No 85-23, revised 2011). The experiments were approved by the Governmental Animal Care and Use Committee (LANUV, Landesamt für Natur Umwelt und Verbraucherschutz Nordrhein-Westfalen, Recklinghausen, Germany) (reference number: 8402.04.2015.A584). Animals were obtained from a commercial breeding facility with consent to use in this study.

\section{Consent for publication}

Not applicable.

\section{Competing interests}

R. E., C.D. K., U.P. N., M. E., M. H., C. K. have nothing to disclose.

A. G., A. M., A. S.-K. report grants to their institution from Fasciotens $\mathrm{GmbH}$ (Cologne, Germany) to conduct the animal-study.

\section{Author details}

'Department of General, Visceral and Transplantation Surgery, RWTH Aachen University Hospital, Pauwelsstraße 30, 52074 Aachen, Germany. ${ }^{2}$ Center for Experimental Medicine, University of Cologne, Robert-Koch-Str. 10 Building No. 51A, 50931 Cologne, Germany. ${ }^{3}$ Department of Surgery, Marienhospital Brühl GmbH, Mühlenstraße, 21-25 50321 Brühl, Germany. ${ }^{4}$ IMSB, University of Cologne, Kerpener Str. 62, 50937 Cologne, Germany. ${ }^{5}$ Decentral Animal Facility, University Hospital of Cologne, Gleueler Str. 24, 50931 Cologne, Germany.

Received: 7 September 2018 Accepted: 24 June 2019

Published online: 08 July 2019

\section{References}

1. Bruhin A, Ferreira F, Chariker M, Smith J, Runkel N. Systematic review and evidence based recommendations for the use of negative pressure wound therapy in the open abdomen. Int J Surg. 2014;12(10):1105-14. https://doi. org/10.1016/j.ijsu.2014.08.396.

2. Open Abdomen Advisory P, Campbell A, Chang M, Fabian T, Franz M, Kaplan M, Moore F, Reed RL, Scott B, Silverman R. Management of the open abdomen: from initial operation to definitive closure. Am Surg. 2009;75(11 Suppl):S1-22.

3. Junge $K$, Klinge $U$, Prescher A, Giboni P, Niewiera M, Schumpelick V. Elasticity of the anterior abdominal wall and impact for reparation of incisional hernias using mesh implants. Hernia. 2001;5(3):113-8.

4. De Waele JJ, Kaplan M, Sugrue M, Sibaja P, Bjorck M. How to deal with an open abdomen? Anaesthesiol Intensive Ther. 2015;47(4):372-8. https://doi. org/10.5603/AIT.a2015.0023.

5. Quyn AJ, Johnston C, Hall D, Chambers A, Arapova N, Ogston S, Amin Al. The open abdomen and temporary abdominal closure systems--historical evolution and systematic review. Color Dis. 2012;14(8):e429-38. https://doi. org/10.1111/j.1463-1318.2012.03045.x.

6. Roberts DJ, Zygun DA, Grendar J, Ball CG, Robertson HL, Ouellet JF, Cheatham ML, Kirkpatrick AW. Negative-pressure wound therapy for critically ill adults with open abdominal wounds: a systematic review. J Trauma Acute Care Surg. 2012;73(3):629-39. https://doi.org/10.1097/TA. Ob013e31825c130e.

7. Willms A, Schaaf S, Schwab R, Richardsen I, Bieler D, Wagner B, Gusgen C. Abdominal wall integrity after open abdomen: long-term results of vacuumassisted wound closure and mesh-mediated fascial traction (VAWCM). Hernia. 2016;20(6):849-58. https://doi.org/10.1007/s10029-016-1534-2.

8. Wondberg D, Larusson HJ, Metzger U, Platz A, Zingg U. Treatment of the open abdomen with the commercially available vacuum-assisted closure system in patients with abdominal sepsis: low primary closure rate. World J Surg. 2008;32(12):2724-9. https://doi.org/10.1007/s00268-008-9762-y.

9. Carlson GL, Patrick H, Amin Al, McPherson G, MacLennan G, Afolabi E, Mowatt G, Campbell B. Management of the open abdomen: a national study of clinical outcome and safety of negative pressure wound therapy. Ann Surg. 2013;257(6):1154-9. https://doi.org/10.1097/SLA. Ob013e31828b8bc8.

10. Cheatham ML, Demetriades D, Fabian TC, Kaplan MJ, Miles WS, Schreiber MA, Holcomb JB, Bochicchio G, Sarani B, Rotondo MF. Prospective study examining clinical outcomes associated with a negative pressure wound therapy system and Barker's vacuum packing technique. World J Surg. 2013; 37(9):2018-30. https://doi.org/10.1007/s00268-013-2080-z.

11. Lambertz A, Mihatsch C, Roth A, Kalverkamp S, Eickhoff R, Neumann UP, Klink $C D$, Junge K. Fascial closure after open abdomen: initial indication and early revisions are decisive factors--a retrospective cohort study. Int J Surg (London, England). 2015;13:12-6. https://doi.org/10.1016/j.ijsu.2014.11.025.

12. Cheatham ML, Safcsak K. Is the evolving management of intra-abdominal hypertension and abdominal compartment syndrome improving survival? Crit Care Med. 2010;38(2):402-7.

13. Miller RS, Morris JA Jr, Diaz JJ Jr, Herring MB, May AK. Complications after 344 damage-control open celiotomies. J Trauma. 2005;59(6):1365-71 discussion 1371-1364. 
14. Vidal MG, Ruiz Weisser J, Gonzalez F, Toro MA, Loudet C, Balasini C, Canales $H$, Reina R, Estenssoro E. Incidence and clinical effects of intra-abdominal hypertension in critically ill patients. Crit Care Med. 2008;36(6):1823-31. https://doi.org/10.1097/CCM.0b013e31817c7a4d.

15. Raeburn CD, Moore EE, Biffl WL, Johnson JL, Meldrum DR, Offner PJ, Franciose RJ, Burch JM. The abdominal compartment syndrome is a morbid complication of postinjury damage control surgery. Am J Surg. 2001;182(6):542-6.

16. Barker DE, Kaufman HJ, Smith LA, Ciraulo DL, Richart CL, Burns RP. Vacuum pack technique of temporary abdominal closure: a 7 -year experience with 112 patients. J Trauma. 2000;48(2):201-6 discussion 206-207.

17. Bee TK, Croce MA, Magnotti $\sqcup$, Zarzaur BL, Maish GO 3rd, Minard G, Schroeppel TJ, Fabian TC. Temporary abdominal closure techniques: a prospective randomized trial comparing polyglactin 910 mesh and vacuumassisted closure. J Trauma. 2008;65(2):337-42; discussion 342-334. https://doi. org/10.1097/TA.0b013e31817fa451.

18. De Waele JJ, Leppaniemi AK. Temporary abdominal closure techniques. Am Surg. 2011;77(Suppl 1):S46-50.

19. Chiara O, Cimbanassi S, Biffl W, Leppaniemi A, Henry S, Scalea TM, Catena F, Ansaloni L, Chieregato A, de Blasio E, Gambale G, Gordini G, Nardi G, Paldalino P, Gossetti F, Dionigi P, Noschese G, Tugnoli G, Ribaldi S, Sgardello S, Magnone S, Rausei S, Mariani A, Mengoli F, di Saverio S, Castriconi M, Coccolini F, Negreanu J, Razzi S, Coniglio C, Morelli F, Buonanno M, Lippi M, Trotta L, Volpi A, Fattori L, Zago M, de Rai P, Sammartano F, Manfredi R, Cingolani E. International consensus conference on open abdomen in trauma. J Trauma Acute Care Surg. 2016;80(1):173-83. https://doi.org/10. 1097/ta.00000000000000882.

20. Hecker A, Hecker B, Hecker M, Riedel JG, Weigand MA, Padberg W. Acute abdominal compartment syndrome: current diagnostic and therapeutic options. Langenbeck's Arch Surg. 2016;401(1):15-24. https://doi.org/10.1007/ s00423-015-1353-4.

21. Hatch QM, Osterhout LM, Podbielski J, Kozar RA, Wade CE, Holcomb JB, Cotton BA. Impact of closure at the first take back: complication burden and potential overutilization of damage control laparotomy. J Trauma. 2011; 71(6):1503-11. https://doi.org/10.1097/TA.0b013e31823cd78d.

22. Burlew CC, Moore EE, Biffl WL, Bensard DD, Johnson JL, Barnett CC. One hundred percent fascial approximation can be achieved in the postinjury open abdomen with a sequential closure protocol. J Trauma Acute Care Surg. 2012;72(1):235-41. https://doi.org/10.1097/TA.0b013e318236b319.

23. Dubose JJ, Scalea TM, Holcomb JB, Shrestha B, Okoye O, Inaba K, Bee TK, Fabian TC, Whelan J, Ivatury RR, Group AOAS. Open abdominal management after damage-control laparotomy for trauma: a prospective observational American Association for the Surgery of Trauma multicenter study. J Trauma Acute Care Surg. 2013;74(1):113-20; discussion 1120-1122. https://doi.org/10.1097/TA.0b013e31827891ce.

24. Hofmann AT, Gruber-Blum S, Lechner M, Petter-Puchner A, Glaser K, Fortelny R. Delayed closure of open abdomen in septic patients treated with negative pressure wound therapy and dynamic fascial suture: the long-term follow-up study. Surg Endosc. 2017. https://doi.org/10.1007/ s00464-017-5547-4.

25. Deeken CR, Lake SP. Mechanical properties of the abdominal wall and biomaterials utilized for hernia repair. J Mech Behav Biomed Mater. 2017;74: 411-27. https://doi.org/10.1016/j.jmbbm.2017.05.008.

26. McLennan CE, McLennan MT, Landis EM. The effect of external pressure on the vascular volume of the forearm and its relation to capillary blood pressure and venous pressure. J Clin Invest. 1942;21(3):319-38. https://doi. org/10.1172/JCl101306

27. Herrman EC, Knapp CF, Donofrio JC, Salcido R. Skin perfusion responses to surface pressure-induced ischemia: implication for the developing pressure ulcer. J Rehabil Res Dev. 1999;36(2):109-20.

28. Brienza DM, Geyer MJ, Jan YK. A comparison of changes in rhythms of sacral skin blood flow in response to heating and indentation. Arch Phys Med Rehabil. 2005;86(6):1245-51. https://doi.org/10.1016/j.apmr.2004.11.038.

29. Criss CN, Petro CC, Krpata DM, Seafler CM, Lai N, Fiutem J, Novitsky YW, Rosen MJ. Functional abdominal wall reconstruction improves core physiology and quality-of-life. Surgery. 2014;156(1):176-82. https://doi.org/ 10.1016/j.surg.2014.04.010.

\section{Publisher's Note}

Springer Nature remains neutral with regard to jurisdictional claims in published maps and institutional affiliations.

\section{Ready to submit your research? Choose BMC and benefit from:}

- fast, convenient online submission

- thorough peer review by experienced researchers in your field

- rapid publication on acceptance

- support for research data, including large and complex data types

- gold Open Access which fosters wider collaboration and increased citations

- maximum visibility for your research: over $100 \mathrm{M}$ website views per year

At BMC, research is always in progress.

Learn more biomedcentral.com/submissions 